\title{
Rheumatoid Arthritis and Total Ankle Joint Replacement
}

\author{
Chaudary B, Mathavan G, Jamal B* and Pillai A \\ Department of Trauma \& Orthopaedics, University Hospitals of South Manchester, UK
}

Received: April 14, 2014; Accepted: September 12, 2014; Published: October 06, 2014

*Corresponding author: Bilal Jamal, 88 Earlspark Avenue, Newlands, Glasgow, G43 2HD, United Kingdom, Tel: +44-758-416-9123; E-mail: bjamal@ doctors.org.uk

\begin{abstract}
Rheumatoid arthritis is a systemic autoimmune condition of unknown etiology which may present to the orthopedic surgeon with multi joint involvement. Rheumatoid arthritis can involve the ankle, hindfoot and forefoot. We review the historical surgical treatments for the rheumatoid ankle. We also discuss the results of the varying generations of total ankle replacement in rheumatoid arthritis. We conclude the results of the latest generation of ankle arthroplasties are limited in the rheumatoid population. This demands a frank discussion between patients and surgeons prior to embarking on surgery.
\end{abstract}

\section{Keywords: Rheumatoid; Arthritis; Ankle; Arthroplasty}

Rheumatoid Arthritis (RA) is an autoimmune disorder of unknown etiology characterized by symmetric, erosive synovitis and in some cases, extra-articular involvement [1].

There are approximately 400,000 people with RA in the UK. The incidence of the condition is low, with around 1.5 men and 3.6 women developing RA per 10,000 people per year. This translates into approximately 12,000 people developing RA per year in the UK. The overall occurrence of RA is two to four times greater in women than men. The peak age of incidence in the UK for both genders is the 70s, but people of all ages can develop the disease [2].

Traditionally, the mainstay of surgical management for advanced degenerative disease of the ankle due to RA has been arthrodesis. Arthrodesis has been shown to be associated with a higher rate of fusion as reported by Maurer when evaluating transarticular cross-screw fixation as a technique for ankle arthrodesis. He reports $100 \%$ fusion rates using the above technique and a lower rate of fusion with charnley compression arthrodesis [3]. This was found to be coupled with good postoperative function [4], however, was associated with ipsilateral foot arthritic changes in the long term [5]. Further adverse effects of ankle fusion such as slowed velocity of gait and shortened length of stride while barefoot have also been noted [4].

In an attempt to try and overcome some of the highlighted problems, ankle arthroplasty has been developed. Historically, first generation designs have been associated with poor outcomes. In 1985, an editorial in the British volume of the
Journal of Bone and Joint Surgery stated that arthroplasty could not be recommended at that time given the available results. He suggested that prior to considering ankle arthroplasty surgery, there have to be improvements in prosthetic design, uncemented implants have to be routinely available and improved surgical technique was required [6].

Second generation ankle replacements were largely uncemented prosthesis with minimal bone resections. They are semi constrained and allow for improved joint kinematics [7]. This prosthesis can be divided into two and three component designs [7]. The three most common second generation ankle replacements commercially available are: Low Contact Stress (LCS), the Agility and the Scandinavian Total Ankle Replacement (STAR) [7]. With further developments, third generation total ankle replacements are now available.

To date, the available studies in relation to Total Ankle Arthroplasty (TAA) in rheumatoid patients are observational in nature which reflects inconsistent survival analysis outcomes between studies. Although studies have reported success rate of $>$ $90 \%$ at 10 years using the STAR and Buechal Pappas (BP) implant [8], this data needs to be interpreted with caution as other studies using such implants are unable to reproduce similar success. Woods et al. [9], an independent high volume unit, compared two different implants (STAR Vs BP) and reported only $79 \%$ six year survivorship of the BP design as compared to $95 \%$ survivorship with the STAR design. This study had a relatively good sample of 200 patients, was a single centre study and was prospective in nature. 62 of the patients in the trial had an underlying diagnosis of rheumatoid arthritis. In a further paper from the same unit, Wood [10] demonstrated an impressive $80.3 \%$ survivorship with the STAR in 200 patients in whom the majority had rheumatoid arthritis. A total of 24 patients had required revision surgery.

San Giovanni et al. [11] at an independent unit reported an overall survivorship of $93 \%$ at a mean 8.3 year follow up using the BP implant. However this was a retrospective review that involved a much smaller sample size of 31 patients with rheumatoid arthritis.

A Norwegian group [12] has demonstrated similarly impressive results, on this occasion principally with the STAR prosthesis, with 10 year data demonstrating $76 \%$ survivorship. 
A systematic review by Zaidi et al. [13] revealed $73 \%$ ten year survival rate in long term registry data as compared to $89 \%$ ten year survival rate in pooled non registry data. The registry results would describe a more realistic expected outcome as compared to non-registry data that may have a strong inventorrelated influence.

The newer ankle arthroplasty designs have abandoned the use of cemented implants following increased failure rates due to component subsidence and early loosening [14]. Kofoed et al. [15] reinforced this in their designer series in 2004 reporting a remarkable $95.4 \%$ survivorship at 12 years with uncemented implants compared to $70 \%$ at 12 years with cemented implants. Patients in this study required ankle arthroplasty due to either underlying osteoarthritis or rheumatoid arthritis

Roukis and Prissel [16] performed an observational analysis of worldwide ankle replacement registry data comprising 13 different ankle replacement systems, involving 6 countries that had available data regarding ankle replacement performed between $2000 \& 2011$. The Mobility ankle replacement was the most frequently implanted replacement system worldwide (33\%) with a significant increase in use since 2007. There was also a significant increase in the usage of newer systems such as Hintegra and Salto Mobile Prosthesis in the last 4 years of the study period. The established STAR system noted a significant decline in usage trend from 179 cases in 2000 to 31 cases in 2011.

The increasing trend of Mobility system over the recent past has only made short and midterm analysis of outcome possible. The initial report of 100 cases using the Mobility system was published in 2010. This study revealed a 93.6\% 4 year survival with a mean follow up of 43 months [17]. This trial assessed the outcomes of the mobility implant in patients with osteoarthritis. Survivorship in a rheumatoid population has not been assessed. Therefore, it is difficult to make comments regarding this implant in such a population.

Table 1 summarizes the results of ankle arthroplasty in patients with rheumatoid arthritis. The number of papers to list is limited due to the small numbers of papers assessing arthroplasty surgery in a rheumatoid population.

\section{Conclusion}

TAA is an established and valid option in patients suffering from ankle joint dysfunction. Despite the availability of newer third generation implants, the available data is limited. The older second generation implant such as the STAR acceptable

Table 1: Results of ankle arthroplasty in patients with rheumatoid arthritis.

\begin{tabular}{|c|c|c|c|}
\hline Author & Implant & Follow up (years) & Survivor ship (\%) \\
\hline Buechel & STAR, BP & 10 & $>90$ \\
\hline \multirow{2}{*}{ Woods } & STAR & 6 & 95 \\
& BP & \multirow{2}{*}{6} & 79 \\
\hline San Giovanni & BP & 8.3 & 93 \\
\hline
\end{tabular}

outcomes; patients and surgeons should be cognizant of the results of surgery prior to embarking on it. Further research is needed to look at long term survival, prosthesis design along with surgical technique in patients who undergo surgery with newer third generation implants.

\section{References}

1. Harris ED Jr. Rheumatoid arthritis: pathophysiology and implications for therapy. N Engl J Med. 1990; 322(18):1277-89.

2. National Institute for Clinical Excellence (NICE). Rheumatoid arthritis: The management of rheumatoid arthritis in adults. [Cited 2014 APR 05]; Available from: http://www.nice.org.uk/guidance/ $\operatorname{cg} 79$

3. Maurer RC, Cimino WR, Cox CV, Satow GK. Transarticular cross-screw fixation. A technique of ankle arthrodesis. Clin Orthop Relat Res. 1991; 268:56-64.

4. Mazur JM, Schwartz E, Simon SR. Ankle arthrodesis. Long-term followup with gait analysis. J Bone Joint Surg Am. 1979; 61(7):964-75.

5. Coester LM, Saltzman CL, Leupold J, Pontarelli W. Long-term results following ankle arthrodesis for post-traumatic arthritis. J Bone Joint Surg Am. 2001; 83-A(2):219-28.

6. Hamblen DL. Editorial: Can the Ankle Joint Be Replaced? J Bone Joint Surg Br. 1985; 67(5):689-690.

7. Jamal B, Halai M, Pillai A. The Evolution of Total Ankle Arthroplasty. Orthop Muscul Syst. 2014; 3:145. doi: 10.4172/2161-0533.1000145.

8. Buechel FF Sr, Buechel FF Jr, Pappas MJ. Ten-year evaluation of cementless Buechel-Pappas meniscal bearing total ankle replacement. Foot Ankle Int. 2003; 24(6):462-472.

9. Wood PL, Sutton C, Mishra V, Suneja R. A randomised, controlled trial of two mobile-bearing total ankle replacements. J Bone Joint Surg Br. 2009; 91(1):69-74. doi: 10.1302/0301-620X.91B1.21346.

10. Wood PL, Prem H, Sutton C. Total ankle replacement: medium-term results in 200 Scandinavian total ankle replacements. J Bone Joint Surg Br. 2008; 90(5):605-9. doi: 10.1302/0301-620X.90B5.19677.

11.San Giovanni TP, Keblish DJ, Thomas WH, Wilson MG. Eight-year results of a minimally constrained total ankle arthroplasty. Foot Ankle Int. 2006; 27(6):418-26.

12. Fevang BT, Lie SA, Havelin LI, Brun JG, Skredderstuen A, Furnes 0. 257 ankle arthroplasties performed in Norway between 1994 and 2005. Acta orthop. 2007; 78(5):575-83.

13.Zaidi R, Cro S, Gurusamy K, Siva N, Macgregor A, Henricson A, et al. The outcome of total ankle replacement: A systematic review and meta-analysis. Bone Joint J. 2013; 95-B(11): 1500-7. doi: 10.1302/0301-620X.95B11.31633.

14. Spirt AA, Assal M, Hansen ST Jr. Complications and failure after total ankle arthroplasty. J Bone Joint Surg Am. 2004; 86-A(6):1172-8.

15. Kofoed H. Scandinavian Total Ankle Replacement (STAR). Clin Orthop Relat Res. 2004; 424:73-9.

16. Roukis TS, Prissel MA. Registry Data Trends of Total Ankle Replacement Use. J Foot Ankle Surg. 2013; 52(6):728-735. doi: 10.1053/j.jfas.2013.08.006.

17. Wood PL, Karski M, Watmough P. Total ankle replacement: the results of 100 mobility total ankle replacements. J Bone Joint Surg Br. 2010; 92(7):958-962. doi: 10.1302/0301-620X.92B7.23852. 